J. P. Oyston MB BS FFARCS,

F. A. Burrows MD FRCPC, J. Lerman MD FRCPC

\title{
Factors influencing the R-R interval during central venous injec- tion in newborn swine
}

Seven Yorkshire swine, ages 7-11 days and weighing 1.4-2.8 $\mathrm{kg}$ were studied to determine the effects of temperature and volume of injectate, depth of anaesthesia, position of the central venous catheter tip and vagotomy on the $R-R$ interval after central venous injection of saline. The swine were anaesthetized with halothane in 100 per cent oxygen and their lungs ventilated to normocapnia. The length of the $R-R$ varied inversely with the temperature of the injectate between $O$ and $20^{\circ} \mathrm{C}$ reaching a maximum prolongation of 152 per cent above control values with $O^{\circ} \mathrm{C}$ saline. Injecting saline at $37^{\circ} \mathrm{C}$ did not affect the $R-R$ interval. The length of the $R-R$ interval varied directly with the volume of injectate between 1.5 and $4.5 \mathrm{ml} \cdot \mathrm{kg}^{-1}(P<0.05)$. The $R-R$ interval response also varied directly with the depth of anaesthesia: the posi-injection $R-R$ interval increased from 185 per cent to 341 per cent as the end-tidal halothane concentration increased from 0.45 to 1.20 per cent. The position of the tip of the central venous catheter that produced the maximum increase in the R-R interval, as determined radiographically, was at the junction of the superior vena cava and the right atrium. Neither bilateral vagotomy nor atropine $\left(50 \mu \mathrm{g} \cdot \mathrm{kg}^{-1}\right)$ affected the $R-R$ interval after injecting $3 \mathrm{ml} \cdot \mathrm{kg}^{-1}$ saline $O^{\circ} \mathrm{C}$. We conclude that the increases in $R-R$ interval after injection of fuid into the right atrium are due to direct effects on the nerve conduction system of the heart, passibly on the sino-atrial node.

\section{Key words}

COMPLICATIONS: arrhythmia; HEART: arrhythmia, pulse rate, thermodilution, sino-atrial node; MEASUREMENT TECHNIQUES: cardiac output, thermodilation, venous pressure; PAPRASYMPATHETIC NERVOUS SYSTEM: vagus; TEMPERATURE: cooling.

From the Department of Anaesthesia and the Research Institute, The Hospital for Sick Children and University of Toronto.

Supported with a grant from the Heart and Stroke Foundation of Ontario.

Address correspondence to: Dr. F. A. Burrows, Department of Anaesthesia, The Hospital for Sick Children, 555 University Avenue, Toronto, Ontario, Canada MSG IX8.
Whole-body cooling produces a bradycardia (increase in $R-R$ interval), which responds poorly to atropine or bilateral vagotomy. ${ }^{1-3}$ The injection of $10 \mathrm{ml}$ of five per cent dextrose at $2^{\circ} \mathrm{C}$ into the right atrial port of a Swan Ganz catheter produces a transient increase in $R-R$ interval ${ }^{4}$ as does the injection of $3 \mathrm{ml}$ of 0.9 per cent $\mathrm{NaCl}$ at $\mathrm{O}^{\circ} \mathrm{C}$ into a central venous catheter in a $2.8 \mathrm{~kg}$ human neonate (personal observation). Similarly, during a study of baroreceptor function in neonatal swine we observed transient increases in the R-R interval after injection of fluid at $22^{\circ} \mathrm{C}$ via a central venous catheter. The factors affecting such changes in the R-R interval at the time of injection of fluid into the right atrium are poorly understood. To clarify this observation further, we studied the effects of temperature of injectate, volume of injectate, depth of anaesthesia, site of the central venous catheter, and parasympathetic nervous system on the R-R interval.

\section{Methods}

With approval from the local Animal Care Committee, seven Yorkshire swine, aged 7-11 days (mean 8.3) weighing $1.4-2.8 \mathrm{~kg}$ (mean $2.0 \mathrm{~kg}$ ) were studied.

Each animal was fasted for two hours preoperatively. Anaesthesia was induced using 70 per cent nitrous oxide in oxygen and halothane and maintained with 100 per cent oxygen and halothane. The trachea was intubated with a tracheal tube, and the lungs were ventilated to maintain normocapnia ( $\mathrm{PrCO}_{2} 45-50 \mathrm{mmHg}$ ) via a Bain circuit and a series 300 Penlon neonatal-paediatric anaesthesia ventilator. The external jugular vein was cannulated with an umbilical artery catheter and ligated proximally under direct vision.

End-tidal gas was obtained by manually aspirating gas through a catheter that was positioned with its tip within 1 $\mathrm{cm}$ of the distal end of the tracheal tube. The end-tidal concentration of halothane was measured using a calibrated Beckman LB2 infra-red anaesthetic gas analyzer and corrected for carbon dioxide. Unless otherwise stated, the swine were equilibrated to an end-tidal concentration of $0.85 \pm 0.05$ per cent (which corresponds to $\approx 1 \mathrm{MAC}$ for neonatal swine) for at least 15 minutes before each study. 
The Beckman LB2 infra-red gas analyzer was calibrated using air containing known concentrations of halothane. The halothane mixtures were prepared by injecting calibrated microlitre volumes of liquid halothane into a large glass bottle of known volume. Before the liquid halothane was injected into the bottle, an aliquot of air was aspirated and analyzed in the LB2 to ensure the bottle was free of halothane. Liquid halothane was then injected into the bottle. Atmospheric pressure was maintained within the bottle by allowing the air mixture to expand freely into a glass syringe. The contents of the bottle were then thoroughly mixed. The LB2 was calibrated using concentrations of halothane between 0.2 and 4.0 per cent (corrected for ambient temperature and pressure). A calibration curve that related the calculated and analyzed halothane concentrations was constructed to correct for alinearity of the LB2 detector. For in vivo measurements the LB2 values were also corrected for the presence of carbon dioxide (concentrations between four and seven per cent) by subtracting 0.01 per cent. Humidification (at $40^{\circ} \mathrm{C}$ ) was shown to have no effect on the LB2 detector.

Core temperature was monitored using a rectal probe. Normothermia $\left(38-39^{\circ} \mathrm{C}\right)$ was maintained using an overhead radiant heater. The ECG was monitored continuously using needle electrodes in a lead II configuration, and was recorded using a Gould four channel recorder at a speed of $25 \mathrm{~mm} \cdot \mathrm{sec}^{-1}$.

Intravenous fluids, normal saline ( 0.9 per cent) (warmed to $37^{\circ} \mathrm{C}$ with a blood warming unit), were administered at a rate of $2 \mathrm{ml} \cdot \mathrm{kg} \cdot \mathrm{hr}^{-1}$ to each swine through a central venous cannula. Venous blood obtained from the central venous cannula was analyzed for blood gases (Corning 175 automatic $\mathrm{pH} /$ blood gas system) every 30 minutes and at each depth of anaesthesia to confirm acid-base homeostasis and $\mathrm{PCO}_{2}$.

The effects of temperature of injectate, volume of injectate, and depth of anaesthesia were studied in six swine. The effect of altering the position of the central venous catheter was studied in one swine. The effects of surgical and chemical vagotomy were studied in three swine each.

Five syringes that contained normal saline (0.9 per cent) were equilibrated at the following temperatures: $0^{\circ}$ $\mathrm{C}, 4^{\circ} \mathrm{C}, 10^{\circ} \mathrm{C}, 20^{\circ} \mathrm{C}$ and $37^{\circ} \mathrm{C}$. The temperature of the saline was monitored using an electrical thermometer (YSI Telethermometer series 400 model 43TD), and was maintained within $0.5^{\circ} \mathrm{C}$ of the designated temperature. Three $\mathrm{ml} \cdot \mathrm{kg}^{-1}$ of the normal saline were injected into the proximal access site of the central venous catheter at a rate of $1 \mathrm{ml} \cdot \mathrm{sec}^{-1}$. This was repeated at each of the five temperatures in a random order. The per cent increase in $\mathbf{R}-\mathbf{R}$ interval was calculated from three consecutive $\mathbf{R}-\mathbf{R}$ intervals before the injection and the three longest consecutive intervals after the injection. Five minutes were allowed for recovery after each saline injection before repeating the procedure with saline at another temperature.

Three volumes of saline $\left(1.5 \mathrm{ml} \cdot \mathrm{kg}^{-1}, 3 \mathrm{ml} \cdot \mathrm{kg}^{-1}\right.$ and $4.5 \mathrm{ml} \cdot \mathrm{kg}^{-1}$ ) were cooled to $0^{\circ} \mathrm{C}$ and injected at the rate of $1 \mathrm{ml} \cdot \mathrm{sec}^{-1} \mathrm{ml}$.second-1 into the central venous catheter. The volumes were administered in a random order five minutes apart. The percent increase in the post-injection $\mathrm{R}-\mathrm{R}$ interval compared with the respective injection interval was calculated.

The swine were ventilated with 100 per cent oxygen and halothane to end-tidal halothane concentrations of 0.45 per cent $(0.5 \mathrm{MAC}), 0.65$ per cent $(0.75 \mathrm{MAC}), 0.85$ per cent (1.0 MAC), or 1.22 per cent (1.5 MAC) in random order. After allowing 20 minutes for equilibration, duplicate samples of end-tidal gas were aspirated manually and the halothane concentrations were determined. Each swine was considered to be equilibrated at the end-tidal concentration when the samples differed by no more than 0.01 per cent. Saline $\left(3 \mathrm{ml} \cdot \mathrm{kg}^{-1}\right)$, cooled to $0^{\circ} \mathrm{C}$ was injected through the central venous catheter, and the increase in R-R interval was compared with preinjection values. The swine was then equilibrated at the next MAC multiple of halothane. After a 20-min equilibration period, the end-tidal halothane concentration was measured and the injection repeated.

To determine the effect of position of the tip of the central line on the R-R interval response, the swine was equilibrated at an end-tidal concentration of 0.85 per cent in 100 per cent oxygen. The central venous catheter was then inserted $10 \mathrm{~cm}$ from the entry point into the external jugular vein. Two $\mathrm{ml} \cdot \mathrm{kg}^{-1}$ of saline at $0^{\circ} \mathrm{C}$ were injected. The catheter was withdrawn in $1-2 \mathrm{~cm}$ increments and the injection was repeated. Five minutes were allowed for recovery between injections and normothermia was reconfirmed. When the catheter was adjusted to the position of maximal increase in $R-R$ interval, the swine was killed with a barbiturate overdose and the position of the tip of the catheter determined by $x$-ray.

To determine the influence of the parasympathetic nervous system on the $R-R$ interval response, three swine were randomly assigned to receive surgical vagotomy and three to receive chemical vagotomy (atropine $50 \mu \mathrm{g} \cdot \mathrm{kg}^{-1}$ ) during 1 MAC halothane anaesthesia in 100 per cent oxygen. Prior to vagotomy, control responses to the injection of $0^{\circ} \mathrm{C}$ saline $\left(3 \mathrm{ml} \cdot \mathrm{kg}^{-1}\right)$ were obtained. The vagus nerve was identified bilaterally at the level of the cricothyroid cartilage and divided. In the other three swine, atropine was injected into the central venous catheter and flushed into the right atrium with $3 \mathrm{ml}$ of saline at $37^{\circ} \mathrm{C}$. Five minutes after completion of the vagotomy, $0^{\circ} \mathrm{C}$ saline $\left(3 \mathrm{ml} \cdot \mathrm{kg}^{-1}\right)$ was injected and the 
TABLE Effect of five variables on the R-R interval (msec)

\begin{tabular}{|c|c|c|c|c|c|}
\hline & $\begin{array}{l}\text { Number of } \\
\text { swine }\end{array}$ & Control & & Study & \\
\hline \multicolumn{6}{|c|}{ Temperature $\left({ }^{\circ} \mathrm{C}\right)$} \\
\hline $37^{\circ}$ & 6 & 426.5 & $(329-464)$ & 445.5 & $(328-472)$ \\
\hline $20^{\circ}$ & 6 & 426 & $(339-461)$ & 593.5 & $(528-709)^{*}$ \\
\hline $10^{\circ}$ & 6 & 433 & $(309-485)$ & 749 & $(656-953)^{n^{+}}$ \\
\hline $4^{\circ}$ & 6 & 441.5 & $(341-472)$ & 771 & $(660-1526)^{*+}$ \\
\hline $0^{\circ}$ & 6 & 418 & $(323-483)$ & 856 & $(709-1877)^{*+}$ \\
\hline \multicolumn{6}{|c|}{ Volume $\left(\mathrm{ml} \cdot \mathrm{kg}^{-1}\right)$} \\
\hline 1.5 & 6 & 395 & $(349.487)$ & 645.5 & $(563-739)^{m}$ \\
\hline 3.0 & 6 & 397.5 & $(353-473)$ & 968.5 & $(660-1861)^{*} \S$ \\
\hline 4.5 & 6 & 397 & $(341.483)$ & 1266.6 & $(1104.3357)^{*} \S$ \\
\hline \multicolumn{6}{|l|}{ MAC halothane } \\
\hline 0.5 & 6 & 395.5 & $(331-563)$ & 631.5 & $(557.976)^{*}$ \\
\hline 0.75 & 6 & 359 & $(315.363)$ & 708.5 & $(567.1168)^{*}$ \\
\hline 1.0 & 6 & 400 & $(323-517)$ & 1106.5 & $(736-1967)^{*}$ \\
\hline 1.5 & 6 & 438.5 & (317-533) & 1095 & $(957-2672)^{*} \neq$ \\
\hline Pre-atropineף & 3 & 476 & $(437-515)$ & 1069 & $(864-1376)^{*}$ \\
\hline Post-atropineT & 3 & 451 & $(435-528)$ & 891 & $(835-1357)^{*}$ \\
\hline Pre-vagotomy & 3 & 483 & $(340-517)$ & 925 & $(656-1531)^{*}$ \\
\hline Post-vagotomy & 3 & 504 & $(351-517)$ & 896 & $(707-1320)^{*}$ \\
\hline
\end{tabular}

Data are medians (range).

* $P<0.05$ compared with control.

${ }^{+} P<0.05$ compared with the immediately adjacent higher temperature. $\ddagger P<0.05$ compared with $0.5 \mathrm{MAC}$.

$\$ P<0.05$ compared with immediately adjacent smaller volume.

$\uparrow 50 \mu \mathrm{g} \cdot \mathrm{kg}^{-1}$.

resultant R-R interval was compared with the prevagotomy values.

Statistical significance $(P<0.05)$ was based on the actual measurements of the R-R interval using the Friedman test for repeated measures of non-parametric data and the Wilcoxon signed-rank test with the Bonferroni correction for multiple pairwise comparison. ${ }^{5}$ Data are summarized as medians and ranges (Table).

\section{Results}

We found that the temperature of the injectate significantly affected the R-R interval (Table). The between temperature comparisons of the control values did not differ significantly. However, the within group comparisons of the $R-R$ interval to control values were prolonged for $20^{\circ}$ $\mathrm{C}, 10^{\circ} \mathrm{C}, 4^{\circ} \mathrm{C}$ and $0^{\circ} \mathrm{C}$ (Table) $(P<0.05)$. The R-R interval was not prolonged after injecting saline at $37^{\circ} \mathrm{C}$. The injection of $0^{\circ} \mathrm{C}$ saline increased the median R-R interval 123 per cent, whereas $4^{\circ} \mathrm{C}$ saline increased the median R-R interval 109.5 per cent. Saline at room temperature $\left(20^{\circ} \mathrm{C}\right)$ increased the median $R-R$ interval 47 per cent (Figure 1, Table).
Conduction disturbances occurred in response to the injection of cold saline $\left(0^{\circ} \mathrm{C}\right)$ in two swine. These disturbances consisted of the occurrence of isolated ventricular ectopics and sinus beats, of a change in the $R$-wave to an RSR configuration and the development of biphasic $\mathrm{T}$-waves.

The volume of $0^{\circ} \mathrm{C}$ injectate directly affected the R-R interval (Figure 2). The larger the volume of saline injected, the greater the increase in R-R interval. The between volume comparisons of the control measurements of the R-R interval did not differ significantly (Table). However, the within volume comparisons of the R-R interval for 3.0 and $4.5 \mathrm{ml} \cdot \mathrm{kg}^{-1}$ of saline increased significantly after injection $(P<0.05)$. The difference between the median increase of 62 per cent in $R-R$ interval with $1.5 \mathrm{ml} \mathrm{kg}^{-1}$ and the 219 per cent increase with 4.5 $\mathrm{ml} \cdot \mathrm{kg}^{-1}$ (at $0^{\circ} \mathrm{C}$ ) was statistically significant $(P<0.05)$.

The greater the depth of anaesthesia, the larger and more variable was the $R-R$ interval response to the injection of $0^{\circ} \mathrm{C}$ saline (Table) (Figure 3). The between MAC comparisons of the control measurements of the $R-R$ interval did not differ significantly. The difference 


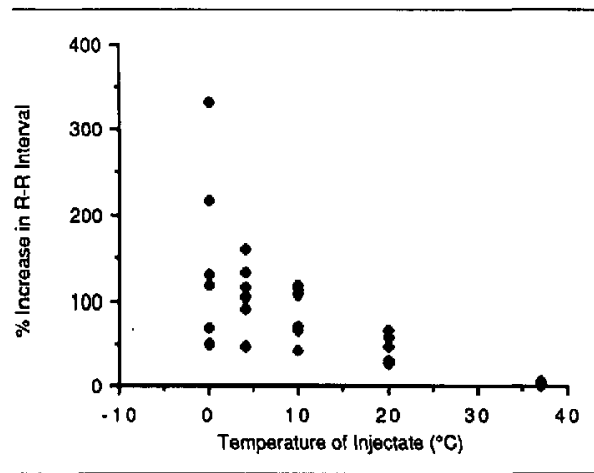

FICURE 1 The per cent increase of the R-R interval as the temperature of injectate (volume $=3 \mathrm{ml} \cdot \mathrm{kg}^{-1}$ ) decreased from $37^{\circ} \mathrm{C}$. The differences among the groups were statistically significant $(P<0.05)$.

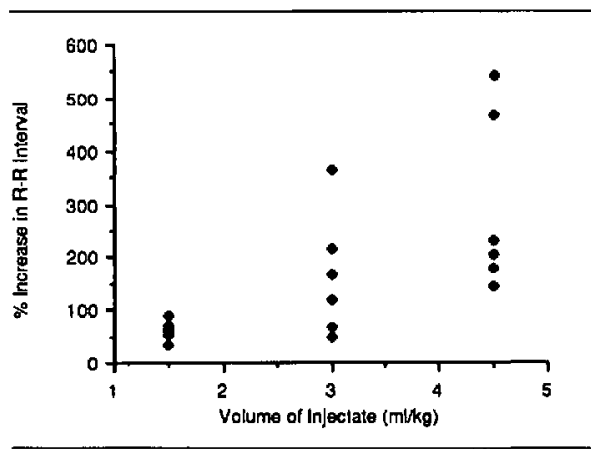

FIGURE 2 The per cent increase of the R-R interval as the volume of injectate at $0^{\circ} \mathrm{C}$ increases. The differences among the groups were statistically significant $(P<0.05)$.

between the $R-R$ interval response to the injection of cold saline at an end-tidal concentration of $0.5 \mathrm{MAC}$ halothane $(0.45$ per cent end-tidal concentration) and 1.5 MAC halothane (1.22 per cent end-tidal concentration) was statistically significant $(P<0.05)$.

The greatest increase in $R-R$ interval occurred when the tip of the line was inserted to a position demonstrated by $x$-ray to be at the junction of the superior vena cava and the right atrium (Figure 4).

Neither surgical nor chemical vagotomy attenuated the increase in $R-R$ interval observed after the injection of cold saline into the central venous catheter (Figure 5).

The magnitude of the bradycardic response varied between the swine. Two swine had dramatic bradycardias

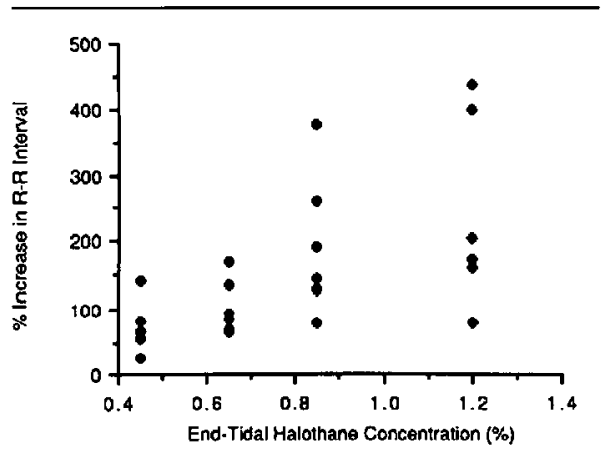

FIGURE 3 The percent increase of the $R-R$ interval from control after injection of $3 \mathrm{ml}$ of 0.9 per cent $\mathrm{NaCl}$ at $0^{\circ} \mathrm{C}$ increases as the end-tidal halothane concentration increases. The difference in the $R-R$ interval increase between $0.5 \mathrm{MAC}$ and 1.5 MAC was statistically significant $(P<0.05)$.

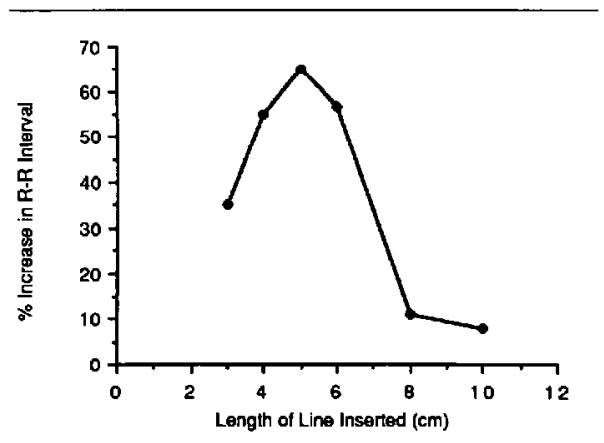

FIGURE 4 The effect of the position of the central venous catheter on the increase in the R-R interval after injection of $2 \mathrm{ml} \cdot \mathrm{kg}^{-1}$ of 0.9 per cent $\mathrm{NaCl}$ at $0^{\circ} \mathrm{C}$. The maximum per cent increase in $\mathrm{R} \cdot \mathrm{R}$ interval occurred when the tip of the central venous catheter was directly opposite the sino-atrial node.

during the studies of temperature and volume of injectate and the effect of depth of anaesthesia, with an average increase in R-R interval of 159 and 238 per cent, while two others had moderate bradycardias with increases in the R-R interval of only 56 and 86 per cent. This could not be accounted for by differences in age, weight, body temperature or resting heat rate, but may have been caused by variation in the position of the cannula.

\section{Discussion}

The use of thermodilution cardiac output measurements in 


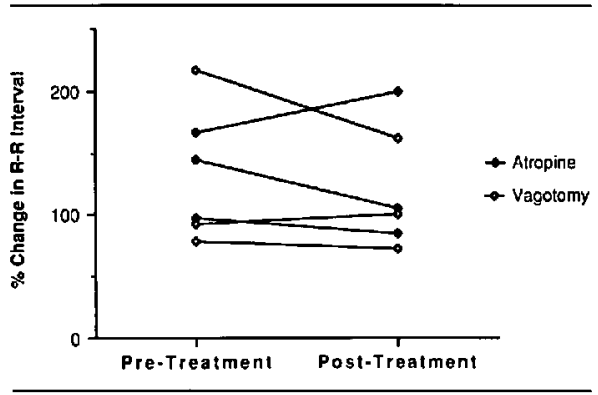

FIGURE 5 The per cent change of the R-R interval after injection of $3 \mathrm{ml} \cdot \mathrm{kg}^{-1}$ of 0.9 per cent $\mathrm{NaCl}$ at $0^{\circ} \mathrm{C}$ before and after chemical (atropine) and surgical vagotomy. There was no statistical difference among the groups with either technique.

the postoperative management of neonates ${ }^{6}$ and infants ${ }^{6-11}$ after repair of congenital heart lesions is increasing. This study demonstrates that the $R-R$ interval increases after the central venous administration of cold saline in newbom swine. The magnitude of the increase in the R-R interval is affected by the temperature and volume of the injectate, the depth of anaesthesia (as determined by end-tidal concentrations) and the position of the tip of the catheter through which the injectate is administered. The increase in R-R interval does not appear to depend on a stretching effect of the right atrial fibres or on a sudden increase in the right atrial pressure after rapid injection of fluid as the R-R interval did not increase after the injection of saline at $37^{\circ} \mathrm{C}$. Similarily, the increase in the R-R interval does not appear to depend on a reflex mediated by the autonomic nervous system as it was not affected by vagotomy.

The mechanism of the increase in R-R interval after injection of fluid into the right atrium may be attributed to a direct cooling effect of cold injectate on the endocardium, most likely on the sino-atrial (SA) node. The effect of temperature on the $\mathrm{R}-\mathrm{R}$ interval is demonstrated in Figure $I$ in which the R-R interval increases as the temperature of the injectate decreases. The injection of $3 \mathrm{ml} \cdot \mathrm{kg}^{-1}$ of injectate at $37^{\circ} \mathrm{C}$ did not significantly effect the R-R interval whereas $1.5 \mathrm{ml} \cdot \mathrm{kg}^{-1}$ of injectate at $0^{\circ} \mathrm{C}$ increased the $R-R$ interval above control values (Figure 1). These data indicate that temperature is more important than the volume of the injectate which is the dominant variable causing prolongation in the $R-R$ interval. The increase in the $R-R$ interval observed after increasing volumes of injectate (Figure 2) is most likely explained by the greater cooling of the endocardium and the SA node with larger volumes of cold injectate. Our observation that the maximum increase in the R-R interval occurs when the tip of the central venous catheter is directly opposite the SA node (Figure 4) provides further evidence that direct cooling of the SA node causes the increase in the R-R interval. This postulate is also supported by previous studies which suggested that the intrinsic rhythmicity of the SA node is reduced by hypothermia. ${ }^{1-3,11-14}$ Marshall ${ }^{11}$ has demonstrated that lowering the temperature of rabbit pacemaker fibres produces a slowing of the atrial rate in association with a decrease in diastolic membrane potential and action potential. Nishikawa et $a^{1{ }^{14}}$ measured the effect of cold injectate through a catheter positioned to deliver the injectate at the junction of the superior vena cava and right atrium (at the level of the SA node) on the myocardial temperature of adult dogs. They demonstrated a strong correlation between the decrease in temperature of the SA node and the decrease in the heart rate. Similarly, the wide variation in our data measurements of the R-R intervals may be explained by variability in the distance between the tip of the central venous catheter and the SA node (Figure 4).

Neither surgical nor chemical vagotomy abolished nor attenuated the increase in R-R interval induced by either decreasing the temperature of the injectate or increasing the volume (Figure 5). We used $250-300 \% \cdot \mathrm{kg}^{-1}$ more injectate than that reported in previous studies. ${ }^{14}$ The purpose of this larger volume was to amplify any possible subtle effects of the autonomic nervous system on the $R-R$ interval. In view of the lack of effect of vagotomy, we conclude that the increase in the $R-R$ interval after injection of saline is not mediated by the parasympathetic autonomic nervous system.

The effect of increasing the end-tidal concentration of halothane on cold-induced prolongation of the R-R interval (Figure 3) has not been reported previously. Reynolds et al. ${ }^{15}$ demonstrated a decrease in diastolic membrane potential and action potential in isolated myocardial fibres during administration of halothane. They also demonstrated a slower diastolic depolarization (Phase 4) and an increase in threshold potential. These effects increased as end-tidal halothane concentration increased and the $S A$ node demonstrates a greater response to the same volume of cold injectate.

The use of thermodilution cardiac output techniques is increasing in popularity for haemodynamic determinations in both clinical and laboratory studies. Nishikawa and Namiki noted the theoretical effect of cooling the SA node on the calculated cardiac output but cautioned that their abservations in dogs may not apply to humans as the ratio of injectate volume to atrial size is smaller in adult humans than in dogs. ${ }^{14}$ However, the ratio of the volume of solution injected to the volume of the atrium is greater in human neonates and infants than in the adult dogs reported by Nishikawa and Namiki. Clinically, we have observed transient bradycardias in neonates and infants in 
whom thermodilution cardiac output measurements were attempted. In this study, we have reproduced these observations in newborn swine. The potential effect of the injectate on the temperature of the SA node and subsequent effect on the accuracy of the thermodilution cardiac output determination must be recognized in clinical and laboratory studies involving small subjects.

In conclusion, we found significant increases in the $R-R$ interval after administration of cold injectate into the right atrium in newborn swine that were augmented by colder temperatures, larger volumes and by increasing depths of anaesthesia with halothane.

\section{Acknowledgements}

We thank Dr. G. Kent and her associates in the animal facilities, Mr. G. Volgyesi for his technical assistance, and Ms. T. Cain for her assistance in preparing this manuscript.

\section{References}

1 Rodgers PD, Webb GP. Cooling to cardiac arrest and resuscitation in anesthetized rats. Physiologist 1982; 25 : 433-7.

2 Bigelow WG, Lindsay WK, Harrison RL, Gordon RA, Greenwood WF. Oxygen transport and utilisation in dogs at low body temperatures. Am J Physiol 1950; 160: 125-37.

3 Cookson BA, DiPalma JR. Severe bradycardia of profound hypothermia in the dog. Am J Physiol 1955; 182 : 447-53.

4 Nishikawa T, Dohis. Slowing of heart rate during cardiac output measurement by thermodilution. Anesthesiology 1982; 57: 538-9.

5 Glantz SA. Primer of Biostatistics. 2nd ed. New York: McGraw-Hill. 1987, 88-90, 302-8, 317-22.

6 Mathur M, Harris EA, Yarrow S, Barratt-Boyes BG. Measurement of cardiac output by thermodilution in infants and children after open-heart operation. J Thorac Cardiovasc Surg 1976; 72: $221-5$.

7 Hickey PR, Hansen DD, Cramoline GM, Vincent RN, Lang $P$. Pulmonary and systemic hemodynamic responses to ketamine in infants with normal and elevated pulmonary vascular resistance. Anesthesiology 1985; 62: 287-93.

8 Hickey PR, Hansen DD, Strafford M, Thompson JE, Jones $R E$, Mayer $J E$. Pulmonary and systemic hemodynamic effects of nitrous oxide in infants with normal and elevated pulmonary vascular resistance. Anesthesiology 1986; 65: $374-8$.

9 Hickey PR, Hansen DD. Fentanyl- and sufentanil-oxygenpancuronium anesthesia for cardiac surgery in infants. Anesth Analg 1984; 63: 117-24.
10 Hickey PR, Hansen DD, Wessel DL, Lang $P$, Jonas RA. Pulmonary and systemic hemodynamic responses to fentanyl in infants. Anesth Analg 1985; 64: 483-6.

11 Marshall JM. Effects of low temperatures on transmembrane potentials of single fibres of the rabbit atrium. Circ Res 1957; 5: 664-9.

12 Clements $S D$, Hurst JW. Diagnostic value of electrocardiographic abnormalities observed in subjects accidentally exposed to cold. Am J Cardiol 1972; 29: 729-34.

13 Conian SW. Accidental hypothermia. Anaesthesia 1978; 34: $250-6$.

14 Nishikawa T, Namiki A. Mechanism for slowing of heart rate and associated changes in pulmonary circulation elicited by cold injectate during thermodilution cardiac output determination in dogs. Anesthesiology 1988; 68: 221-5.

15 Reynolds $A K$, Chiz JF, Pasquet $A F$. Halothane and methoxyflurane. A comparison of their effect on cardiac pacemaker fibers. Anesthesiology 1970; 33: 602-10.

\section{Résumé}

Afin de déterminer les effets de la température du volume injecté, la profondeur de l'anesthésie, la position du bout du catheter veineux central et de la vagotomie sur l'intervalle $R-R$ aprés une injection intraveineuse par voie centrale, sept porcs Yorkshire, agés de 7-II jours et pesant de 1.4-2.8 kg ont été étudiés. Les porcs ont été anesthésiés avec l'halothane et 100 pour cent d' oxygène et ventiles pour atteindre une normocapnie. La longueur de l'espace de l'intervalle $R-R$ était inversement proportionnelle à la température du liquide injecté pour des températures variant de 0 et $20^{\circ} \mathrm{C}$ atteignant un maximum de prolongation de 152 per cent du contrôle d $0^{\circ} \mathrm{C}$. Le salin injecté a $37^{\circ} C$ n'a pas affecté l'intervalle $R-R$. La longueur de l'intervalle $R-R$ variait directement avec le volume du salin injecté entre des valeurs de $1.5 \$ 4.5 \mathrm{ml} \cdot \mathrm{kg}^{-1}(P<0.05)$. Cet intervalle $R-R$ a aussi varié directement avec la profondeur de l'anesthésie: après l'injection cet intervalle augmenta de 185 pour cent d 341 pour cent quand la concentration d' halothane en fin d'expiration augmenta de 0.45 a 1.20 pour cent. La position du bout du cathéter veineux central qui produisit le maximum d'augmentation de l'intervalle $R \cdot R$, déterminée radiologiquement, était à la jonction de la veine cave supérieure et l'oreillette droite. Ni la vagotomie bilatérale ou l'atropine $\left(50 \mu \mathrm{g} \cdot \mathrm{kg}^{-1}\right)$ n'ont affecté I'intervalle $R-R$ aprés l' injection de $3 \mathrm{ml} \cdot \mathrm{kg}^{-1} \mathrm{a}^{\circ} \mathrm{C}$ de salin. On conclut que les augmentations de I'intervalle $R-R$ aprés injection de liquide dans l' oreillette droite sont dues aux effets directs sur le système de conduction nerveux du caur possiblement au niveau du noeud sinusal. 